\title{
Design of Vehicle Integrated Electronic System's Reliability Based on Optimal Redundancy
}

\author{
Liao Zili \\ Department of Control Engineering,Academy of Armored \\ Force Engineering \\ Beijing, China, 100072 \\ Gao Qiang \\ Department of Control Engineering,Academy of Armored \\ Force Engineering \\ Beijing, China, 100072 \\ gq900526@163.com
}

\begin{abstract}
The concept and anslysis method of vehicle integrated electronic system are introduced. The paper does the analysis of topology and reliability by a example of a certain type of vehicle integrated electronic system. According to the optimal design principle,the paper analyzes the system's reliability and verifies the feasibility and validity of the optimal redundant method in vehicle integrated electronic system.
\end{abstract}

Keywords-vehicle integrated electronic system, reliability, optimal redundancy

\section{INTRODUCTION}

As the vehicle integrated electronic system is becoming increasingly important in information transmission and directing operations in the digitized battlefield, its research of reliability has become more important. The reliability of vehicle integrated electronic system includes the reliability of data transmission and the reliability of system. The reliability of data transmission is measured through error rate of the frame; the reliability of system is measured through system reliability and $\mathrm{MTBF}^{[1]}$.The research of its reliability is mainly from the external environment, software protocol and bus network architecture design. The paper begins the preliminary study and evaluation of the vehicle integrated electronic system's reliability mainly from the aspect of the bus network topology. Through redundant design ${ }^{[2-4]}$ to the important nodes of a certain type of armored vehicle integrated electronic system and combined with the best design principle, it begins the preliminary evaluation and design of the reliability of the systemarchitecture.

\section{THE DEFINITION AND ANALYSIS METHOD OF VEHICLE INTEGRATED ELECTRONIC SYSTEM'S RELIABILITY}

\subsection{The definition of vehicle integrated electronic system's reliability}

Vehicle integrated electronic system consists of task terminals, subsystems of function nodes and bus system. According to the concept of reliability, which is the ability to complete the required function of the product within the

\author{
Chen Xixia \\ The General Hospital of Chinese People's Armed Police \\ Forces \\ Beijing, China,100039 \\ Chen Yongxing \\ Department of Control Engineering,Academy of Armored \\ Force Engineering \\ Beijing, China, 100072
}

specified condition and predetermined time, the reliability of vehicle integrated electronic system is the capability of the bus network system and its components completing corresponding function in the specified condition and predetermined time (the provision refers to specified environmental condition and us age condition, etc).

\subsection{The analysis method of system's reliability}

Fault Tree Analysis(FTA) ${ }^{[5]}$ is an analysis method which can classify various fault reas ons of the system from the whole to part, from the top to down by the tree, and connect different parts together through logical relationship.

FTA is an alternative of reliability block diagram. Rather than analysis to the product, it is from the perspective of failure of the system to analy ze various types of failure events, and reflects the logical relationship between the end of the event and system failure. On the other hand, the system's unreliability is the probability of the top event of fault tree happens. Fault tree which is builded simply is shown in Figure 1. In the figure, the top event is connected through the middle result $\mathrm{A}, \mathrm{B}, \mathrm{C}$ and $\mathrm{D}$. And each result event is connected by its corresponding plurality bottom events.

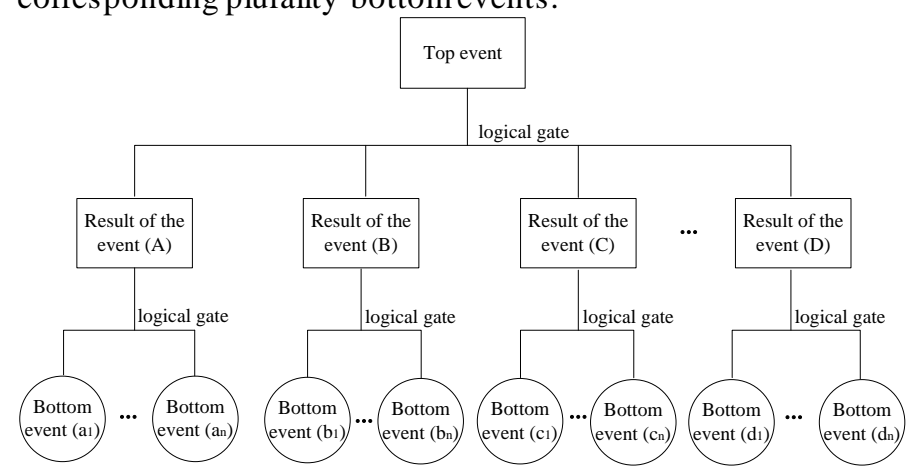

Figure 1 the diagram sketch of fault tree 


\section{THE TOPOLOGY STRUCTURE'S ANALYSIS AND FAULT TREE'S BUILDING OF A CERT AIN T YPE OF VEHICLE INTEGRATED ELECTRONIC SYSTEM}

\subsection{Topology structure of the system}

A typical vehicle integrated electronic system consists of occupant task terminals, node subsystems, data bus , external devices and other components. Each node subsystem is modular in design so as to ensure the node module failure only affects the work of this module and the backup function is not affected by other modules. The paper does evaluation and analysis of reliability for a certain type of armored vehicle integrated electronic system's architecture. To facilitate the analys is, the paper simplifies the topology in Figure 2.

The system consists of crew mission terminal, bus, electrical control subsystem, protection subsystem, navigation subsystem, weapon navigation subsystem and machine information subsystem including central charge and discharge gas node, power module acquisition controller and crew cabin Acquisition Controller.

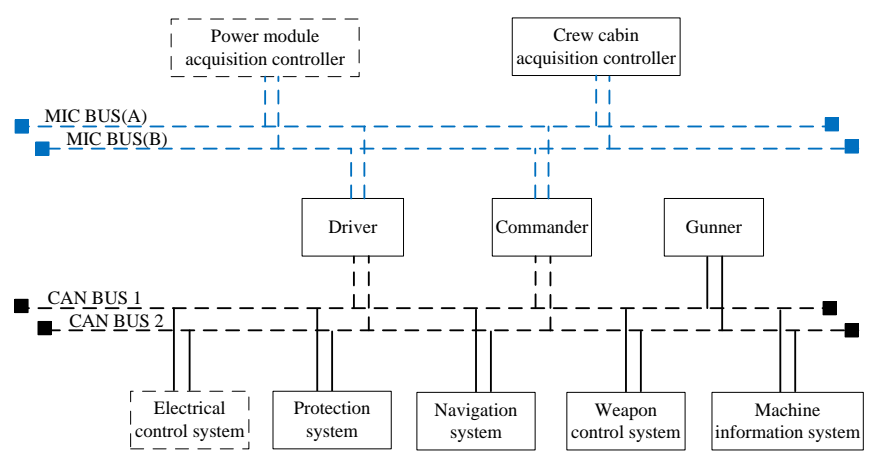

Figure 2 the topology structure of a certain type of vehicle integrated electronic system

\subsection{Fault tree of the system}

The logic gates of vehicle integrated electronic system include or, and, backup gate which is consist of thermal reserve gate and cold reserve gate. To analyzing and comparing the available degree and failure rate of the system, the article built a certain type of vehicle integrated electronic system's fault tree according to its logic relationship. Because its topology is complex, The paper carries out "four" division according to the top-level design.

1) The first layer is the vehicle integrated electronic system's failure;

2) The second Layer has three parts, which are bus fault events, the bus network subsystem's failure and the crew task terminal's failure;

3) The third Layer is further classified according to the second layer;

4) The forth layer is the end of the events and do a more detailed classification based on the third layer.

\subsection{Analysis of the system's reliability and failure rates}

Setting the vehicle integrated electronic system is repairable, failure rate $\left(\lambda_{i}\right)$ of each unit (i) is a constant.Table 1 shows each unit's failure rate of vehicle integrated electronic system, $R(W)$ is the reliability of a certain unit, $W$ is the failure unit. Formula 1 is the reliability of a certain type pf vehicle integrated electronic system according to the system's fault tree.

$$
\begin{aligned}
R(A)=\{1 & -\left[1-\left(2 e^{-0.0002 t}+2 e^{-0.0006 t}-2 e^{-0.0007 t}-e^{-0.0003 t}-e^{-0.0007 t}\right.\right. \\
& \left.\left.\left.+e^{-0.0008 t}\right)\right]\left(1-e^{-0.0005 t}\right)^{2}\right\} \times\left[1-\left(1-e^{-0.001 t}\right)^{12}\right] \times e^{-0.003 t}
\end{aligned}
$$

\begin{tabular}{|c|c|c|c|}
\hline $\begin{array}{l}\text { Equipment and } \\
\text { Nodes }\end{array}$ & Price/10000 yuan & $\mathrm{MTBF} / \mathrm{h}$ & Failure Rate \\
\hline $\begin{array}{c}\text { Driver, } \\
\text { commander, } \\
\text { gunner mission } \\
\text { computer }\end{array}$ & 8 & 2000 & 0.0005 \\
\hline $\begin{array}{l}\text { Driver, } \\
\text { commander, } \\
\text { Gunner display } \\
\text { and control } \\
\text { terminal }\end{array}$ & 2 & 2000 & 0.0005 \\
\hline MIC bus A、B & 3 & 10000 & 0.0001 \\
\hline CAN bus $1 、 2$ & 0.5 & 2000 & 0.0005 \\
\hline $\mathrm{BC}$ & 1 & 2000 & 0.0005 \\
\hline $\begin{array}{l}\text { Backup bus } \\
\text { controller }\end{array}$ & 2 & 10000 & 0.0001 \\
\hline $\begin{array}{l}10 \text { function } \\
\text { nodes contain } \\
\text { Power supply } \\
\text { system, three } \\
\text { anti-system and } \\
\text { so on }\end{array}$ & 1 & 1000 & 0.001 \\
\hline $\begin{array}{l}\text { Power cabin, } \\
\text { crew cabin } \\
\text { acquisition } \\
\text { controller }\end{array}$ & 1 & 1000 & 0.001 \\
\hline
\end{tabular}

Table 1 failure rates of vehicle integrated electronic system's unit

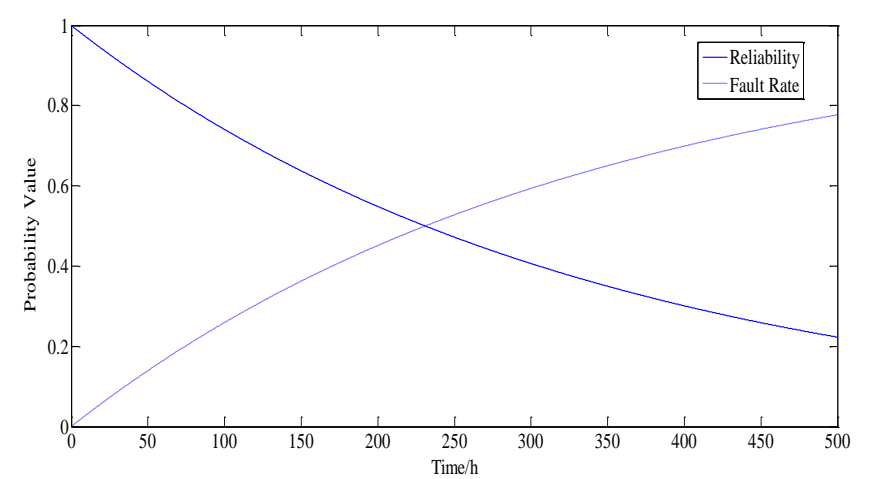

Figure3 Reliability curve of vehicle integrated electronic system

Figure 3 shows reliability and failure rates of a kind of vehicle integrated electronic system.With time goes, the failure rate increases and the reliability decreases.The probability decreases down to $22 \%$ when time is $500 \mathrm{~h}$, the system's reliability is lower at this time. 


\section{THE REDUNDANT DESIGN OF A CERT AIN TYPE OF VEHICLE INTEGRATED ELECTRONIC SYSTEM'S RELIABILITY}

\subsection{The theory of redundant design}

\subsubsection{The introduction ofredundant design}

The system's reliability can be improved by paralleling components, the so-called redundant design. And the parallel system is called redundant system. In consideration of the topology structure of vehicle integrated electronic system, redundant design can be divided into the following three parts: redundant bus, redundant occupant task terminals and redundant nodes subsystem. The manner of connecting of redundant bus is double bus connection, which ensures the system's favorable reliability.The design of redundant occupant task terminals is important because of the significance of occupant task terminal in vehicle integrated electronic system. Node subsystems are usually designed modularizedly.

\subsubsection{The optimaldesign}

Redundancy is good when a single component can't meet the required reliability. System's reliability is in proportion to the quantities of redundant components, but redundancy will raise the system's cost and volume, and the system's flexibility may be reduced. Thus, It is important for optimal design ${ }^{[6]}$ to plan extra prime cost, the size of components and the weight of components.

Assuming that there are $\mathrm{n}$ panel points in integrated electronic system. The reliability of node or system which number is " $\mathrm{i}$ " is $\mathrm{R}(\mathrm{i})$, and $\mathrm{m}_{\mathrm{i}}$ is the cost of panel point or bus which nu mber is " $i$ " , $v_{i}$ is the volume of panel point or bus, $w_{i}$ is the weight of panel point or bus, gi is the quantities of panel point or bus, $m$ represents the whole available cost of redundant design, $v$ represents the extra redundant volume, w represents extra redundant weight, then the constraint condition in system's reliability design is as follows:

$$
\left\{\begin{array}{l}
\sum_{i=1}^{n}\left(m_{i} g_{i}\right) \leq m \\
\sum_{i=1}^{n}\left(v_{i} g_{i}\right) \leq v \\
\sum_{i=1}^{n}\left(w_{i} g_{i}\right) \leq w \\
i=(1,2, \cdots n)
\end{array}\right\}
$$

\subsection{The analysis and design of the case}

The paper improves system's reliability from the point of topology structure.In order to improve the system's reliability,you can improve or change the topology structure,use the redundant design on current topology structure and finally improve the reliability of bus network by building redundant network. The current CAN controller with double buses is the redundancy of bus part. Besides,redundant design can be used in the design of the main occupant task terminals to ensure the favorable reliability.But economic factor should be considered because of its high cost.
The reliability design in vehicle integrated electronic system can be divided into the following three aspects: redundant bus, redundant occupant task terminals, redundant node subsystems. The redundant design of bus is not to be considered because of vehicle's structure of double redundant buses.Taking redundant occupant task terminals and redundant node subsystems into account. Assuming that there are 100 thous and to be used in redundant design, the price and MTBF of every redundant occupant task terminal and node are shown in table 1.

The constraint condition is:

$$
\left\{\begin{array}{l}
\sum_{i=1}^{15}\left(m_{i} g_{i}\right) \leq 10 \\
i=(1,2 \cdots 15)
\end{array}\right\}
$$

According to the optimal design principle and constraint conditions, the optimal answer can be gotten by calculating formula (1), just as the formula (4) shows.

$$
\left\{\begin{array}{l}
g_{i}=0(1 \leq i \leq 15, i \neq 14) \\
g_{i}=1(i=14)
\end{array}\right\}
$$

It indicates that commander task terminal uses redundancy and other nodes don't use redundancy. Figure 4 shows that the comparison between optimal redundancy design system and original vehicle integrated electronic system.

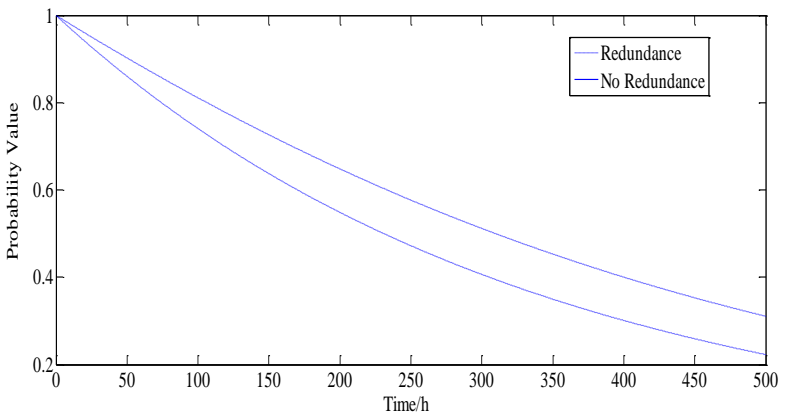

Figure 4 Contrast curve between optimal redundant design system and original system

According to figure 4, the system's reliability is improved to about $32 \%$ when the time is $500 \mathrm{~h}$. Besides,adding fault diagnosis function, performance analysis function to redundant occupant task terminals in order to manage vehicle integrated electronic system easier can also be considered. And those functions will be achieved by programming with software.

\section{CONCLUSION}

Based on a certain type of vehicle integrated electronic system, The paper simplifies its topology reasonably. And the system's fault tree is built according to the function of each part and the reliability and failure rate of the system are acquired.The method of redundancy is used on commander task terminal through optimal design principle and this greatly increases the system's reliability at the same cost.The optimal design can guarantee the validity and feasibility of system's redundant design. 


\section{REFERENCE}

[1] Wang Weixing,Jiang Liqiang,Zhang Zhenyou,et al.Dynamic planning method of reliability distribution for weapon system[J].Journal of Gun Launch \&Control,2006(1):54-57

[2] Fu Lingli,Li Zhijun.The application and reliability analysis of excitation equipment with dual redumant CAN network[J].Electrical Machine Technology,2010(5):60-62

[3] Lu Yuchuan,et al.Design of dual CAN dus redundancy gateway on vehicle[J].Vehicle \& Power Technology,2012(1):45-50
[4] Yang Liang,et al.The design of redundant CAN bus system[J].Development \& Innovation of Machinery \& Electrical Products, 2007,20(5):4-5

[5] J.R. Chang,et al. The reliability of general vague fault-tree analysis on weapon systems fault diagnosis[J]. Soft Comput ,2006(10): 531-542

[6] Chang Junjie,Ye Shu.Reliability deisgn of vehicle -borne network system based on redundancy technology[J].Command Information System and Technology,2012,3(2):49-53 